\title{
Online, Instructional Television And Traditional Delivery: Student Characteristics And Success Factors In Business Statistics
}

\author{
Douglas P. Dotterweich, East Tennessee State University, USA
}

Carolyn F. Rochelle, East Tennessee State University, USA

\begin{abstract}
Distance education has surged in recent years while research on student characteristics and factors leading to successful outcomes has not kept pace. This study examined characteristics of regional university students in undergraduate Business Statistics and factors linked to their success based on three modes of delivery - Online, Instructional Television (ITV), and Traditional classroom. The three groups were found to have similar GPAs prior to taking their statistics courses. Online students were more likely to be repeating the course, to have earned more credit hours prior to enrolling, and to be significantly older. Ordinary Least Squares regression identified GPA and \% absences (or an effort proxy) as highly significant predictors of course performance. Academic advisors are encouraged to suggest a traditional format to students who are repeating the course and to caution students that previous online coursework may produce expectations that are not appropriate for online courses in statistics.
\end{abstract}

Keywords: Statistics Education; Repeating Statistics; Distance Learning

\section{INTRODUCTION}

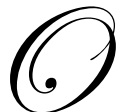

ver 5.6 million students took at least one online class from U. S. institutions in the fall of 2009 compared to 1.6 million in the fall of 2002 (Allen and Seaman, 2010). Higher education institutions are offering an increasing percentage of their courses, and even total degree programs, in online and other nontraditional formats. Defined as "any learning that takes place with the instructor and student geographically remote from each other" (Phillips, 2008), distance learning encompasses extremely diverse delivery methods. Examples of distance course formats include: 1) correspondence courses conducted by mail; 2) traditional classroom teaching with off-site synchronous broadcasts; 3 ) hybrid courses taught in a classroom where students are required to complete online homework or quizzes; 4) online courses that can be taken asynchronously by viewing videos of lectures, doing online homework and taking paper examinations; and 5) fully online classes where all material is posted and completed online at the student's convenience. Many factors, such as increasing familiarity with technology, scheduling issues for nontraditional students, and rising transportation costs, ensure that distance learning will continue to play a prominent role in higher education. Research on student characteristics and factors leading to successful outcomes in these formats has not kept pace.

Undergraduate statistics presents a significant challenge for many students and their professors regardless of delivery method. This may be the result of what Onwuegbuzie and Wilson (2003, p. 196) defined as statistics anxiety, "a feeling which occurs when a student encounters statistics in any form at any level." Finney and Schraw (2003) made the claim that one's self-efficacy concerning statistics plays an important role in attitudes on the subject, as well as performance in statistics courses. This study is unique in that it analyzed both student characteristics and success factors for Business Statistics taught in three formats - a traditional classroom setting, ITV where traditional classroom lectures were synchronously broadcast off-site, and an online format which allowed asynchronous viewing of lecture videos, online homework and in-class paper examinations. 


\section{LITERATURE REVIEW}

Most research has focused on factors affecting overall course performance in traditional courses. For example, Cohn (1972) studied student performance in Economic Statistics, a traditional class with 43 upper level or graduate economics majors. GPA and credits in mathematics positively impacted performance, while credits in economics were negatively related to performance. Rochelle and Dotterweich (2007) found class attendance, previous performance in algebra and differential calculus, and overall GPA upon entry into the course were significantly related to student performance in Business Statistics.

A developing literature on analysis of student performance in distance learning versus the traditional classroom has produced somewhat mixed results. Lawrence and Singhania (2004) analyzed Business Statistics student performance in distance learning versus traditional courses and found that distance learning students did not perform as well. In this study, the distance learning experience involved 40 pre-recorded PowerPoint modules as well as a CD with lectures. Farinella (2007) found that students in the online section of introductory finance underperformed students in traditional sections of the same course.

In the majority of the recent literature on Business Statistics and student performance, the method of delivery was not observed to significantly impact student learning (McLaren, 2004; Schou, 2007; Utts, Sommer, Acredolo, Maher, and Matthews, 2003; and Ward, 2004). McLaren (2004) studied persistence (completion of the class) and performance in online and classroom Business Statistics. Although fewer online students persisted to completion of the course, for those who did, final grade was independent of the mode of instruction. Schou (2007) took great care in employing a similar structure in teaching an online and traditional section of Business Statistics during the same summer term. For example, videos of the lecture material were provided online and the same software and homework assignments were used in both modes of instruction. Although the sample sizes were quite small, no significant difference was found in the final exam scores in the two sections. Utts et al. (2003) compared a traditional offering of elementary statistics with a hybrid offering and found that performance in the hybrid offering was comparable to that in the traditional offering. Ward (2004) also compared demographics of entering students as well as course performance of a traditional elementary statistics offering with a hybrid version using a somewhat broader measure of performance (tests, quizzes, projects, and final exam grades). This study found no significant differences in either category: demographics or course performance.

The current study is unique in that it examined three modes of delivering Business Statistics (traditional, online, and instructional television) within a single study. This allowed the authors to control for institution and instructor. Previous studies have been limited to either a single course method or no more than two methods of delivery for the same course.

This study addressed two major issues with respect to the teaching of Business Statistics. First, were there significant differences in the characteristics of students who enrolled in sections with different modes of delivery? Second, did the predictors of student performance vary by mode of delivery? Literature that aided in identifying variables for the present study included Dutton, Dutton, and Perry (2002), Dutton and Dutton (2005), McLaren (2004), and Rochelle and Dotterweich (2007). The authors included two additional variables not found in the literature, Earned Hours and Repeat Business Statistics, based on classroom experience.

\section{METHODOLOGY}

In order to examine both student characteristics and success factors for Business Statistics taught in a traditional classroom, online and via ITV, multiple sections of Business Statistics taught by two professors at a midsize regional state university were selected for analysis. Three data sets - traditional classroom (57 students), online (59 students), and ITV (48 students) - were constructed from 2004 through the summer of 2008. The classes selected were comparable in many ways. Since all classes utilized the departmental course learning objectives, there was a common body of material presented. The instructors used the same text, chose to cover the topics in the same order, and pacing of the material was similar. Excel was used for most statistical calculations in all sections. Both instructors required students to calculate some problems by hand, placed significant emphasis on the interpretation of statistical results for business policy, and administered similar examinations. The online classes, as might be expected, utilized online homework while the other sections did not. Online students took traditional paper exams, 
either at the home campus or in a proctored environment. These samples included all students who completed the course for each section of the class. All data was obtained through instructor records of student performance and university records. Since data was aggregated, the university Institutional Review Board (IRB) determined that student consent was not required.

Five numerical variables and four categorical variables were included in the current study to investigate the two research questions. Analysis of Variance and Chi-Square tests were employed to determine whether significant differences in student characteristics existed upon entry to the course by mode of delivery. Then, Ordinary Least Squares (OLS) regression was run on the factors impacting academic success, as measured by final course average, to see which proved significant in predicting performance for each mode of delivery. The needed assumptions of linearity, independence, normality, and equal variances were tested for the residuals from each of the models, and they were found to be in the acceptable range (with the exception of equal variances for the Age variable).

The variables are provided in Table 1 along with their corresponding summary statistics. The variables included in the model were as follows.

\section{Numerical Variables}

\section{GPA (Prior to course entry)}

This variable was studied to determine whether there might be any self selection bias in mode of delivery based on a student's GPA. One study (Dutton and Dutton, 2005) found that students with a higher GPA upon course entry were more likely to prefer the online section. It was also anticipated that students with a higher overall GPA were likely to perform better in Business Statistics. The mean Grade Point Averages of students entering Business Statistics on a 4.0 scale were 2.82 (traditional), 2.92 (online), and 2.89 (ITV).

Age

The average ages of students in online versus traditional sections of Computer Science (Dutton et al., 2002) and Business Statistics (Dutton and Dutton, 2005 and McLaren, 2004) were found to be greater in the online sections. This may be due to the need for greater flexibility in scheduling classes on the part of older students. However, a study by Bill (2003) indicated that older students (those 25 or older) often possess greater statistics anxiety than younger students. This may result in older students preferring the familiarity of a traditional classroom over either ITV or online. Consequently, the authors were unsure what to expect concerning age and type of section. Students' average ages were 23.16 with a standard deviation of 3.70 (traditional), 25.81 with a standard deviation of 6.83 (online), and 23.96 with a standard deviation of 5.57 (ITV). Note that standard deviations are provided for $A g e$ because analysis showed a significant difference in variances.

Table 1: Summary Statistics

\begin{tabular}{|c|c|c|c|c|c|c|}
\hline \multicolumn{7}{|l|}{ Independent Variables } \\
\hline & \multicolumn{2}{|c|}{ Traditional Classes } & \multicolumn{2}{|c|}{ Online Classes } & \multicolumn{2}{|c|}{ ITV Classes } \\
\hline Variable & Mean & Std Dev & Mean & Std Dev & Mean & Std Dev \\
\hline GPA & 2.82 & 0.57 & 2.92 & 0.46 & 2.89 & 0.59 \\
\hline Age & 23.16 & 3.70 & 25.81 & 6.83 & 23.96 & 5.57 \\
\hline Earned Hours & 77.26 & 24.66 & 85.42 & 29.44 & 73.10 & 26.72 \\
\hline Absences \% & 7.64 & 7.63 & & & 10.9 & 10.1 \\
\hline \multirow[t]{2}{*}{ Homework Minutes Online } & & & 617.34 & 393.80 & & \\
\hline & Proportion & & Proportion & & Proportion & \\
\hline Gender - Female & 0.46 & & 0.61 & & 0.54 & \\
\hline Repeat Business Statistics & 0.14 & & 0.37 & & 0.10 & \\
\hline Previous Online Class & & & 0.25 & & & \\
\hline Previous ITV Class & & & & & 0.60 & \\
\hline \multicolumn{7}{|l|}{ Dependent Variable } \\
\hline & Mean & Std Dev & Mean & Std Dev & Mean & Std Dev \\
\hline Final Average & 79.13 & 11.27 & 77.66 & 10.9 & 73.83 & 16.38 \\
\hline
\end{tabular}




\section{Earned Hours}

Student earned hours prior to course entry was not mentioned in the literature. Ward (2004) examined student classification (freshman, sophomore, junior, and senior) and found no difference in classification for a traditional versus hybrid elementary statistics course. By using the number of earned hours as a more precise measure of collegiate experience, the authors felt that greater experience with a variety of instructors and methods, professional and personal commitments, and other factors may increase the chances of upperclassmen signing up for non-traditional methods of delivery. Average earned hours in the current study were 77.26 (traditional), 85.42 (online), and 73.10 (ITV).

\section{Absences \%}

Prior research (Dutton, et al., 2002), (Dutton and Dutton, 2005), (Rochelle and Dotterweich, 2007) indicated that class attendance is an important factor in course performance. The mean percentages of absences were 7.6 (traditional) and 10.9 (ITV). This variable did not apply to online students. It was anticipated that increased student absences lower the expected final average.

\section{Homework Minutes Online}

Course Compass, the classroom management system used, tracks length of time spent online in the Business Statistics homework module. The mean time was 617.34 minutes for the semester with a standard deviation of 393.80 minutes. Homework minutes online was used as a weak proxy for attendance for online students. Being online does not insure that a student is actively working on the assignment nor does less time spent necessarily indicate less effort. With its limitations, the authors still anticipated that more homework minutes online would improve class performance.

\section{Categorical Variables}

\section{Gender}

The literature suggested that the importance of gender as a student characteristic may vary by subject area. In a study of computer science students, Dutton et al. (2002) found no difference in the proportion of males or females enrolled by type of course. Two other studies (McLaren, 2004), (Dutton and Dutton, 2005) found a higher proportion of females in the online sections of Business Statistics courses. Since the current study analyzed Business Statistics, the authors anticipated a higher proportion of females in the online sections. The proportions of females were .46 (traditional), .61 (online), and .54 (ITV). Prior research (Dutton and Dutton, 2005; Rochelle and Dotterweich, 2007) indicated no difference in performance of males and females in Business Statistics.

\section{Repeat Business Statistics}

Students are required to complete Business Statistics with a minimum grade of $\mathrm{C}$ at the study institution. About $30 \%$ of students do not complete the course with a satisfactory grade and are required to retake it. The authors were interested in determining whether students who were retaking the course were more likely to opt for a particular format. This variable has not been addressed in the previous literature in Business Statistics. The proportions of students repeating Business Statistics were .14 (traditional), .37 (online), and .10 (ITV). The authors expected previous exposure to course material to result in higher grades the second time.

\section{Previous Online Course}

Twenty five percent of online students in the current study had taken a previous online course. Based on familiarity with technology, it was expected that previous online experience should result in improved course performance. 


\section{Previous ITV Course}

Sixty percent of ITV students had taken a previous ITV course. Based on classroom experience, it was expected that previous ITV experience should result in higher grades in Business Statistics.

\section{EMPIRICAL RESULTS}

\section{Student Characteristics}

Differences in student characteristics based on mode of delivery in Business Statistics were analyzed using Analysis of Variance for numerical data and a Chi-Square Test for Proportions for categorical data. Table 2 shows the results of these tests.

Table 2: Panel A - Student Characteristics - Ratio Data ANOVA \& Tukey-Kramer

\begin{tabular}{|c|c|c|}
\hline \multicolumn{3}{|c|}{ ANOVA Results } \\
\hline Variable & F-value & Significance Level \\
\hline GPA & 0.559 & .572 \\
\hline Age & 3.508 & .032 \\
\hline Earned Hours & 2.92 & .057 \\
\hline \multicolumn{3}{|c|}{ Tukey-Kramer Results } \\
\hline Variable & Difference & Significance Level \\
\hline $\begin{array}{ll}\text { Age } & \text { Trad. - ITV } \\
\end{array}$ & -0.80 & .741 \\
\hline Trad. - On Line & -2.66 & .029 \\
\hline ITV - On Line & -1.85 & .199 \\
\hline Earned Hours Trad. - ITV & 4.16 & .713 \\
\hline Trad. - On Line & -8.16 & .238 \\
\hline ITV - On Line & -12.32 & .053 \\
\hline
\end{tabular}

Table 2: Panel B - Student Characteristics - Categorical Data Chi-Square and Marasculio Procedure

\begin{tabular}{|l|c|c|}
\hline \multicolumn{2}{|c|}{ Chi-Square Results } \\
\hline Variable & $\chi^{2}-$ Value & Significance Level \\
\hline Gender & 2.773 & .250 \\
\hline $\begin{array}{l}\text { Repeat Business Statistics by Delivery } \\
\text { Method }\end{array}$ & 14.163 & .001 \\
\hline \multicolumn{2}{|c|}{ Marasculio Results } \\
\hline Variable & Difference & Significant Differences \\
\hline Rep. Bus. Stat. Trad. - ITV & 0.036 & .051 \\
\hline Trad. - On Line & -0.233 & .002 \\
\hline ITV - On Line & -0.269 & \\
\hline
\end{tabular}

$G P A$

There was no significant difference in mean GPA for the three groups.

Age

The average age of the online sections was significantly older (mean 25.81 versus 23.16) than for the traditional class. Since the variances for ages for the three methods of delivery were found to be significantly different, a separate variance $t$ test was performed for each pair of variables, confirming the mean differences found with the Analysis of Variance procedure. 
Gender

Differences in gender by class type were not statistically significant, however, the sample proportions of females .46 (traditional), .61 (online), and .54 (ITV), were consistent with the results mentioned previously by McLaren (2004) and Dutton and Dutton (2005) who reported a higher proportion of females in the online sections.

\section{Earned Hours}

Online students entered the course with a statistically significant difference in earned hours compared to ITV students (85.42 versus 73.10). This is approximately a semester's worth of credit hours.

\section{Repeat Business Statistics}

The proportion of online students repeating business statistics (.37) far exceeded the proportions of traditional students (.14) and ITV students repeating (.10) the course. After getting behind in their plan of study by performing poorly in Business Statistics, it appeared that many students chose the increased flexibility of online when retaking the required course. These choices may have been a result of increased confidence in attempting statistics in an online format as well as work, other classes, family responsibilities and distance.

\section{Success Factors}

Secondly, success factors in Business Statistics were examined across the three delivery methods. A separate OLS backward elimination regression model was run for each data set - traditional classroom, online class, and ITV class - to determine which independent variables were significantly related to the dependent variable Final Average. While final course average is not a perfect measure (if available, a measure of student competencies in learning objectives would be valuable), the course expectations for all three modes of delivery with the two instructors were similar. Backward elimination, where the first step allows a view of all the $\mathrm{x}$ variables adjusted for all other $\mathrm{x}$ variables, was selected in order to provide an initial overview of the model. Performed at a level of .10, this model allowed the researchers to observe all the variables in the equation once before any were eliminated. Thus the authors believe that backward elimination is a good method to find the simple model nested within the general model. All results were confirmed with a stepwise regression model.

The empirical results for the final backward elimination model for each data set are shown in Table 3 . The coefficients and corresponding $\mathrm{p}$ values are reported for significant variables. Adjusted $\mathrm{r}$ square and $\mathrm{F}$ statistics, as well as $\mathrm{p}$ values, are provided for the three regression results.

Table 3: Empirical Results - Success Factors

\begin{tabular}{|c|c|c|c|}
\hline & Traditional & Online & ITV \\
\hline & $\begin{array}{c}\text { Coefficient } \\
\text { (p value) }\end{array}$ & $\begin{array}{c}\text { Coefficient } \\
\text { (p value) }\end{array}$ & $\begin{array}{c}\text { Coefficient } \\
\text { (p value) }\end{array}$ \\
\hline \multicolumn{4}{|l|}{ Variable } \\
\hline GPA & $\begin{array}{l}11.795 \\
(.000)\end{array}$ & $\begin{array}{l}9.633 \\
(.000)\end{array}$ & $\begin{array}{c}14.828 \\
(.000)\end{array}$ \\
\hline Absences \% & $\begin{array}{l}-0.672 \\
(.000)\end{array}$ & & $\begin{array}{l}-0.414 \\
(.038)\end{array}$ \\
\hline Homework Minutes Online & & $\begin{array}{l}0.005 \\
(.051)\end{array}$ & \\
\hline Repeat Business Statistics & $\begin{array}{l}6.207 \\
(.047)\end{array}$ & & \\
\hline Previous Online Course & & $\begin{array}{l}-4.647 \\
(.045) \\
\end{array}$ & \\
\hline Adjusted R Square & 0.554 & 0.288 & 0.422 \\
\hline F Statistic (p value) & $\begin{array}{c}24.149 \\
(.000)\end{array}$ & $\begin{array}{l}8.812 \\
(.000)\end{array}$ & $\begin{array}{c}18.188 \\
(.000)\end{array}$ \\
\hline $\mathbf{N}$ & 57 & 59 & 48 \\
\hline
\end{tabular}


All models explained a considerable amount of variation in final grades of Business Statistics students as shown by the adjusted $\mathrm{r}$ squares: Traditional: $\mathrm{r}^{2}=.554$, Online: $\mathrm{r}^{2}=.288$ and ITV: $\mathrm{r}^{2}=.422$. While the adjusted $\mathrm{r}$ square value for online students was lower than for the other modes of delivery, it provided a result which is of practical value to instructors of Business Statistics. The authors suspect that the lower adjusted $r$ square for online students was the result of the use of a limited proxy for attendance - online homework minutes.

GPA was highly significant for all three modes of delivery. Holding all other variables constant (which results in a net regression coefficient), a one point higher GPA, on a 4.0 scale, estimated a mean percentage increase in Final Average of 11.795 (traditional), 9.633 (online), and 14.828 (ITV).

Additionally, Absences \% was highly significant for the two modes of delivery, traditional classroom and ITV, where attendance was expected. The net regression coefficients were -.672 (traditional) and -.414 (ITV), indicating that mean Final Average is expected to decrease by .672 (traditional) and .414 (ITV) for each additional percentage increase in a student's absences. The significance of GPA and Absences \% confirms previous research (Rochelle and Dotterweich, 2007).

In the online class, Homework Minutes Online was significant, albeit small, with a net regression coefficient of .005 . This factor served as a limited proxy for attendance for online students by measuring effort expended on the class. Thus, the significance of absences/attendance or its proxy was consistent for all three modes of delivery of Business Statistics.

There were important differences in success factors in Business Statistics among the modes of delivery. First, students repeating the course had an advantage in a traditional classroom setting. The net regression coefficient of Repeat Business Statistics suggested that the average final grade was about six percent higher for those students who were repeating. This advantage did not extend to either ITV students or online students as the net coefficient was insignificant. Since online students were more likely to be repeating Business Statistics than other students, this information can be used in advising students registering for Business Statistics.

Secondly, Previous Online Class indicated that online students who had taken an online class in another subject area had an average final course grade which was 4.6 percent lower than those without previous experience in an online environment. The authors attributed this to the unique character of quantitative courses. Students who have taken a more descriptive online course and done well may have a false sense of confidence on entering a statistics class. It may be more difficult for one to learn quantitative material in an individualized and self motivated framework. This suggests that those students with previous online course experience might be informed of this finding prior to registering for online statistics.

Before concluding, it is important to mention those variables that were not related to student outcomes in any of the modes of delivery of Business Statistics. Neither Gender nor Age was correlated with course performance for any of the three data sets. These findings should be encouraging to both students and advisors as individuals consider outside responsibilities and scheduling issues when registering for Business Statistics. While Earned Hours was significantly greater for students taking Business Statistics online, it was not a predictor of success for any of the three modes of delivery. Finally, Previous ITV Course appeared to have no significant impact on success in Business Statistics for those students choosing that option.

\section{CONCLUSIONS AND RECOMMENDATIONS}

The analysis revealed that a significantly higher proportion of online students were repeating Business Statistics than those enrolled in a traditional or ITV class. Consequently, online students tended to have more earned credits and be significantly older on average before taking the required course.

OLS regression analysis was employed to determine success factors in Business Statistics. Higher GPA resulted in a higher grade for all three groups. Increased Absences \% resulted in poorer course performance for both traditional and ITV classes while increased Homework Minutes Online (as a proxy for attendance) yielded better outcomes for online students. 


\section{Academic Advisors}

These findings led to several concrete recommendations for academic advisors:

- $\quad$ Students repeating Business Statistics may benefit by taking the course in a traditional rather than nontraditional (ITV or online) environment.

- $\quad$ Students without previous online exposure in other courses did not experience any disadvantage in taking Business Statistics online. In fact, students should be alerted that previous online experience may produce expectations that are not appropriate for this type of course.

- $\quad$ Regardless of gender or age, those students who need the flexibility of online or ITV classes to complete their education may find it to be a good option.

\section{Course Instructors}

This paper also suggests a specific recommendation to instructors of statistics courses. Instructors of traditional or ITV sections might encourage or reward students who attend class regularly while online instructors could recommend that students spend significant time working on the online homework before each exam. These measures of effort are strongly related to course performance.

\section{LIMITATIONS AND DIRECTIONS FOR FUTURE RESEARCH}

Three specific modes of delivery of Business Statistics were examined in this study. Are the factors that influence performance the same for other methods of delivery such as correspondence courses or hybrid courses that combine traditional components with online homework and quizzes? What about fully online classes that do not have any physical meetings?

The results and the model developed in this paper are not likely to be generalizable to non-statistics courses. However, the results were quite consistent with those of previous studies of Business Statistics, as well as statistics generally.

Two variables that had not been examined previously in the literature, Earned Hours and Repeat Business Statistics, are likely to be important in future examinations of student characteristics by mode of instruction and performance in Business Statistics.

Final Average was selected as the measure of course performance. If data were available, a study that utilized a measure of student competency in course learning objectives would transcend differences in instructors and, therefore, be worth additional study.

Online Homework Minutes was used as a proxy for attendance in the current study. There may be several reasons for variation in number of minutes. A study that employed a better measure of effort for non-traditional classes would be a valuable contribution to the literature.

Immediacy of instructor feedback has been shown to impact attitude of online students (Schou, 2007). Perhaps performance of online Business Statistics students might also be better explained by including an examination of student characteristics such as attitude toward the subject matter, maturity and additional responsibilities outside of class. The inclusion of these factors in future studies might help to explain more of the variation in student performance.

Interaction effects were not specifically investigated in this study. An analysis of interactions, such as gender or age with other variables, might provide useful insights to Business Statistics professors and advisors.

Finally, a study providing more detail on all students' prior experience in nontraditional courses would be beneficial. For example, a study that examined the proportion of traditional students with previous online and ITV experience, the proportion of online students with previous ITV experience, and the proportion of ITV students with 
previous online experience would add further insight into choices students make. A better understanding of these choices might improve the advisement process for all students.

\section{AUTHOR INFORMATION}

Douglas P. Dotterweich is a Professor of Economics and the Eastman Credit Union Fellow at East Tennessee State University. He received his B.A. degree from the University of Tennessee and his M.A. and Ph.D. degrees from the University of Delaware in Urban and Regional Economics. His research interests include the areas of teaching business statistics, factors impacting migration in higher education and regional economics. E-mail: dotterwe@etsu.edu. Corresponding author.

Carolyn F. Rochelle is a Lecturer of Economics and has been teaching Business Statistics since 1990 at East Tennessee State University. Ms. Rochelle received a B.S. in Mathematics at Tennessee Technological University and an MBA at ETSU. Her research interests primarily focus on teaching Business Statistics and Economics. Additional research areas include pension funding and university student migration patterns. E-mail: rochelle@etsu.edu.

\section{REFERENCES}

1. Allen, I.E., \& Seaman, J. (2010). Class Differences Online Education in the United States, 2010. Babson Park, MA: Babson Survey Research Group, 2.

2. Bill, J. A. (2003). Statistics Anxiety: The Non-Traditional Student. Education, Fall, online.

3. Cohn, E. (1972). Students' Characteristics and Performance in Economic Statistics. Journal of Economic Education, Spring, 106-111.

4. Dutton, J., Dutton, M., \& Perry, J. (2002). How Do Online Students Differ From Lecture Students? Journal of Asynchronous Networks [Online] (6), 1. www.sloan-c.org/publications/jaln/v6n1/v6n1_dutton.asp

5. Dutton, J. \& Dutton, M. (2005). Characteristics and Performance of Students in an Online Section of Business Statistics. Journal of Statistics Education, 13, (3), 1-26.

6. Farinella, J. (2007). Professor and Student Performance in Online Versus Traditional Introductory Finance Courses. Journal of Economics and Finance Education, 6(Summer), 40-47.

7. Finney, S. J. \& Schraw, G. (2003). Self-efficacy Beliefs in College Statistics Courses. Contemporary Educational Psychology, 28, 161-186.

8. Lawrence, J. A., \& Singhania, R. P. (2004). A Study of Teaching and Testing Strategies for a Required Statistics Course for Undergraduate Business Students. Journal of Education for Business, 79, (6), 333338.

9. McLaren, C. H. (2004). A Comparison of Student Persistence and Performance in Online and Classroom Business Statistics Experiences. Decision Sciences Journal of Innovative Education, 2, (Spring), 1-10.

10. Onwuegbuzie, A. J., \& Wilson, V. A. (2003). Statistics Anxiety: Nature, Etiology, Antecedents, Effects, and Treatments - A Comprehensive Review of the Literature. Teaching in Higher Education, Vol. 8, 195209.

11. Phillips, V. (2008). The Virtual University Gazette's FAQ on Distance Learning, Accreditation, and Other Degrees. Retrieved August 18, 2008 from http://www.geteducated.com/articles/dlfaq.asp.

12. Rochelle, C. F., \& Dotterweich, D. (2007). Student Success in Business Statistics. Journal of Economics and Finance Education, 6 (Summer), 19-24.

13. Schou, S. B. (2007). A Study of Student Attitudes and Performance in an Online Introductory Business Statistics Class. Electronic Journal for the Integration of Technology in Education, Vol. 6, 71-78.

14. Utts, J., Sommer, B., Acredolo, C., Maher, M.W., \& Matthews, H. M. (2003). A Study Comparing Traditional and Hybrid Internet-Based Instruction in Introductory Statistics Classes. Journal of Statistics Education, Vol. 11, (3).

15. Ward, B. (2004). The Best of Both Worlds: A Hybrid Statistics Course. Journal of Statistical Education, $12,(3)$. 
NOTES 